CASE STUDY:

\title{
MULTICULTURAL FACTORS AND THE REPRESENTATION OF ACID ATTACK SURVIVORS IN INDIAN SOCIETY BASED ON MULTIMODAL DISCOURSE ANALYSIS
}

\author{
S.Aswini CHITHRA \\ iD: https://orcid.org/ 0000-0001-6988-0470 \\ SRM Institute of Science and Technology (SRMIST), India
}

\author{
Archana ARUL \\ iD: https://orcid.org/ 0000-0001-6973-3454 \\ SRM Institute of Science and Technology (SRMIST), India
}

(C) The Author(s) 2021

\section{ABSTRACT}

Women considered to the goddess nature and praised in the form of Land and Rivers, but struggle to buy bread and basics in day today life. Women face violence everywhere in every form such as domestic, gang rape, acid throwing, and sexual violence at work place, dowry death and forced abortion. Acid Attack is worldwide and it is considered to be the most abominable form of gender based violence against women. According to India Today Data Intelligence Unit (DIU) the statistics released by National Crime Records Bureau shows between 2014 and 2018, states that there have been 1,483 victims of acid attack happened in the country. The Victims are taunted, shamed and disfigured for no fault on theirs. It is the need of the hour to examine the gender based violence against Women in India; its cause and consequence, as this is an untold tale in the subparts of the country. On the other hand, Indian Cinema is an effective mass communication medium and continues to evolve. There is always a strong bonding between cinema and Indian Society as it is a cultural role player for Indian Audience as well as immigrants where it promotes the uniqueness of multiculturalism of Indian Society.. The role of Women in Indian Cinema acted between the dichotomy of passive subject and Pleasurable Object. Indian New wave made a shift in the screen and contributed dialogues to women's role and position. Women became a subject on lens. The representation of women in Indian cinema still endures with controversy and characterized by diverse interpretations in our Multicultural land. This paper aims to examine the Representation of acid attack survivors in Indian Cinema qualitatively with the help of case studies and Multimodal discourse analysis by interpreting with the Interactive and compositional meaning.

(C) 2021.All rights reserved.

ARTICLE HISTORY

Received:

17 November, 2020

Accepted:

8 February, 2021
Published:

25 April, 2021

Available online:

25 April, 2021
KEYWORDS

Acid Attack, Gender based Violence, Indian Cinema, and Multimodal discourse 


\section{Introduction}

Patel (2014) In south Asia, disputes over declined Marriage proposals, land, dowries, inheritance often ends in violence, which also leads to acid violence and women becomes the first victims of it. Digging deeper with the perspective of India on its Multicultural grounds, practicing diverse Ethnic groups and Minority religions, Reitman (2005) A critical analysis is conducted in the academics to find the root cause on culturally diverse society like India and its relationship with multiculturalism and Feminism; McKerl (2007) and critiquing Multiculturalism by particularly investigating act of Violence by Men against Women. The aim of acid attack is not to kill the human but to kill the beauty and disfigure the face which also leads to lose the eye sight. The victims face severe physical injuries and traumatized mentally. Acid throwing rarely kills the human but causes severe physical, social and psychological scarring.

Cinema on the other hand plays a paramount role in injecting certain ideologies and values. On this context Interrelating the prescribed norms and values analyzing through Mulvey's (1999) "Visual Pleasure and Narrative Cinema" it states that the women objectified or passive as the beauty doll, mother, and goddess and showcases her perfect. But very few movies in Indian cinema voices out the sufferings of women in reality and shows the violence against them.

\section{Indian scenario}

Though Acid attack is a crime, which can be committed against any men or women, in India it has a gender dimension. Law commission of India in July 2009 States acid attacks are mostly committed against women especially young women on rejection of marriage proposals or for denying dowry etc., Acid attack is carried out as an discriminatory act. As many cases go unreported and no specific statistics available, According to India Today Data Intelligence Unit (DIU) the statistics released by National Crime Records Bureau shows between 2014 and 2018, states that there have been 1,483 victims of acid attack happened in the country. And Australian Broadcasting Corporation states that India has the highest incidence of acid attacks in the world, Where 300 acid attacks are reported in India each year. 


\section{Causes and Consequences}

Unlike other weapons which are illegal and hard to find Acid is easily available in market and easy to acquire. The common causes for acid attack violence are:

- Cultural - Factors on basis of gender, class inequalities, revenge and as an act of misogyny.

- Societal - Impunity toward perpetrators, social permissiveness and male dominated resources are common factors.

- Situational - The geographic condition, low education, family conflicts, peer association, and the cost of acid.

- Personal - Intrapersonal feelings on powerlessness, male shame, poor anger management, antisocial behavior.

\section{Review of literature}

Hafeez (2016) States that Violence has increased both in Society as well as in Films. The impact of media messages to the society is gradual, subtle. And desensitization effect of violence in movies is also identified widely.

Okin (1999a) Defines Multiculturalism as preserving the status Quo of the Patriarchy in special reference to minority patriarchy and Outlines three Option: a) minority rights, b) assimilation and c) feminist cultural reform as on understanding the notion of multiculturalism and cultural difference need to be taken into account on feminist reasons where the distinctive patriarchal forms leaves unchecked the feminist policies arising in the differently situated (minority) patriarchal norms and referents.

(Finley, 2013) Acid attack leads to a catastrophic impact on the lives of the victim in terms of physical, psychological and financial. The aim of all the acid attack is not to kill but to disfigure or injure.

\section{Objective}

The main objective of the research paper is to study how reality is represented in the portrayal of acid attack victims, survivors in Indian Cinema by using Qualitative multimodal discourse analysis of the selected films with case studies by examining the factors such as causes, consequences, feelings and thought of the survivors and whether the violence against women roots up with multiculturalism. 


\section{Research question}

To study how reality and cultural factors is represented in the portrayal of acid attack survivors in Indian Cinema.

\section{Research design}

To study the representation of reality of the acid attack survivors, Qualitative methodology is applied. As Qualitative research implicates collecting and analyzing non numerical data such as text, video or audio, this methodology is basically used to understand opinions, concepts or experiences to gather in-depth insights in the proposed research question. For this paper two qualitative research methods are applied One is the Case study on the acid victim survivors in India and another one is Multimodal discourse analysis to analyze whether the selected films represent the reality of not.

Case Study research method is commonly used to do an in-depth investigation on a event or a single individual or group to explore the causes. Case study is exploratory as well as descriptive.

Multimodal discourse analysis is a new and rapidly developing discourse analysis since 1990's which includes five levels: Culture, Context, meaning, form and media. Based on the research framework of this paper multimodal discourse analysis will be done on the perspective of context of culture, context of situation and meaning of image.

Ideology, genre, theme and modality of the film will be analyzed in context with culture. Field of discourse, mode of discourse, and tenor of discourse will be analyzed in context with situation and the meaning of image will be interpreted on the basis of representational, interactive and compositional modes.

\section{Samples}

Three Indian movies are picked for the study. As on Today's date only the selected samples portray the life of acid attack victims and survivors as the lead character and the plot revolves on acid attack its causes and consequences. The selected movies are (2012) Vazhakku en 18/9 in Tamil, (2019) Uyare in Malayalam and (2020) Chhapaak in Hindi. 


\section{Interpretation and analysis}

\section{Real Life Cases}

Reshma Qureshi at 2014 was attacked by throwing acid on face brutally by four men which includes her brother in law. And Laxmi Agarwal at the age of 15 was attacked by her acquaintances as she refused to marry him so went on for seven surgeries. Laxmi Agarwal was with Chhanv foundation a culmination for the stop acid attack campaign. Anmol Rodriguez was victim of acid attack from her two months as the acid was aimed to her mother by her father. Dolly a 12 year old girl was attacked by a man who was double her age and stalked her and harassed her.

\section{Multimodal Discourse analysis of the selected samples}

In the context of culture in Multimodal discourse analysis, while analyzing through the cultural factors in Indian Context by highlighting the Race, religion or ethnic factors, the Multiculturalism is not exhibited. The selected samples only portray the acid attack as a gender based violence, crime as an act of misogyny and revenge. The movie Vazhakku en $18 / 9$ adds an additional element on class inequality stating that the weaker sections are vulnerable.

In the context of Situation, analyzing through field of discourse which states the real situation, the movie Chhapaak is based on the real life story of Laxmi Agarwal. The other two movies are fictional but state the fact that the perpetrators are close acquaintances.

Mode of Discourse is analyzing the language, image, sound and sensory organs. In the selected samples the acid throwing scene approximately takes 1 minute of screen time which is intense and show how the victim will suffer, portrayed through the high pitch voice of shouting out of pain and burning sensation and the background music adds more intense to the scene.

The tenor of discourse is stated through the dialogues. In the Last scene of Vazhakku en 18/9 Jyothi says to Velu "See your face" Malti in Chhapaak saying to Anmol when he was not happy with the celebration of the amendment $326 \mathrm{~A} \& \mathrm{~B}$ "Acid is thrown on me and not on you, I myself feel like partying" and Uyare When Vishal Chandrasekaran CEO of Cloud9 airlines says "She has a Brain and Heart; this is 2019 Can we start defining beauty in this way" and when Pallavi Raveendran states to the lawyer "This is my reality; I have to hide the face for rest of my life" is intense with the real life situation, showing the agony and grief. 
In the meaning of Image on the multimodal discourse analysis the representational is embodied by action, reaction and mental Process. Whereas Interactive meaning is created through point of view, attitude and compositional, which is a combination of representational and interactive meaning. In the selected samples Shawl is a symbol of hesitation and shyness to cover the scar. In Chhapaak and Uyare the survivor removes the shawl once she is achieved with her goal and career.in Chhapaak throwing away the shawl is shown as symbol of revolution. And Mirror is another symbol where both in Chhapaak and Uyare seeing the face after getting burnt the reaction of the survivors is so intense and in-depth showing the reality to accept the scar for no sin on their own.

In the compositional meaning victory is shown both in Chhapaak and Vazhakku en 18/9 as the case is reinvestigated on the ladders of courtroom and the perpetrator is getting punished whereas in Uyare the story ends without showing the consequence the perpetrator is facing.

\section{Conclusion}

Based on Multimodal Discourse analysis, the selected three samples were analyzed from the perspective of Context of Culture, Context of Situation and Meaning of Image. While Interpreting the selected films on specific context, image, language and culture construct Multimodal discourse and advocates the selected samples portray the acid attack as a gender based violence, crime as an act of misogyny and revenge with heightening the real life situation, showing the agony and grief not including the Multicultural Factors of Indian Society. Through this research paper, we suggest that as India's uniqueness holds with its Ethnicity and multiculturalism, this can also be included in showing the factors which dominate or subordinate women on minority Patriarchal structure as mentioned by Okin (1999a) in "Is Multiculturalism Bad for Women?"

\section{Disclosure statement}

No potential conflict of interest were reported by the authors. 


\section{References and notes:}

Bhattacharyya, R. (2015). Understanding the spatialities of sexual assault against Indian women in India. Gender, Place \& Culture, 22(9), 1340-1356.

Hafeez, Erum. (2016). The portrayal of Violence in Bollywood Movies and its Effects on Real-life Violence \& Crimes against Women in Pakistani Society. 14. 197-213.

Mandy McKerl (2007) Multiculturalism, Gender and Violence, Culture and

Religion, 8:2, 187-217, DOI: 10.1080/14755610701424032

Mamta Patel. A Desire to Disfigure: Acid Attack in India. International Journal of Criminology and Sociological Theory, Vol. 7, No. 2, December 2014, 1-11

Okin, S.M. (1999a) „IsMulticulturalism Bad For Women?', in J. Cohen, M. Howard and M.C. Nussbaum (eds) Is Multiculturalism Bad For Women?, pp. 7-24. Princeton, NJ: Princeton University Press.

Oonagh Reitman. Multiculturalism and feminism. Ethnicities, SAGE Publications, 2005, 5 (2), pp.216247. ff10.1177/1468796805052117ff. ffhal-00571842f

https://www.abc.net.au/news/2019-08-24/indian-acid-victims-want-to-break-down-socialstigma/11428952

https://www.indiatoday.in/diu/story/india-saw-almost-1-500-acid-attacks-in-five-years-16361092020-01-12 